\title{
Die Struldbrugs
}

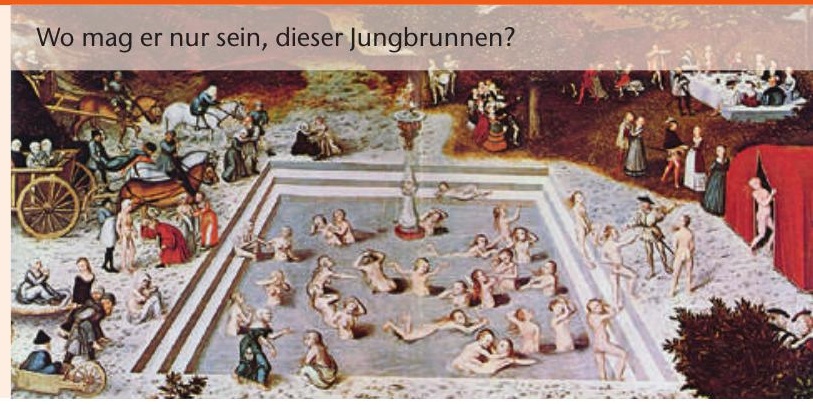

Erhard Taverna

erhard.taverna[at]saez.ch
Die Medizin tut sich schwer mit Sterben und Tod. Wie kann es auch anders sein, ist sie doch nur die Dienerin der Gesellschaft. Der Schriftsteller und Satiriker Jonathan Swift hat sich auf seine Art damit auseinandergesetzt. Gulliver segelt als Schiffsarzt nach Ostindien und hört im Lande Luggnagg von einer Spezies Unsterblicher, den Struldbrugs. Er ist begeistert und träumt von einem grossartigen Leben, sollte ihm das gleiche Schicksal zuteilwerden. Bald darauf lernt er diese Menschen kennen, von denen der Jüngste gerade seinen zweihundertsten Geburtstag hinter sich hat: Die Enttäuschung ist gewaltig: «Niemals hat mich etwas mit tieferem Grauen erfüllt als der Anblick dieser Geschöpfe.» Seine Begleiter wissen es besser. Nur ein Wahnsinniger könne ein Lebenssystem entwerfen, das ewige Jugend, Gesundheit und nie versiegende Energie voraussetze. Die Struldbrugs sind ein unausstehlicher Haufen gieriger, selbstbezogener Trottel. Sie werden von Staates wegen geschieden, da man den Daueraufenthaltern nicht zumuten will «durch die Last eines unsterblichen Weibes doppelt bestraft zu sein».

Der Wunsch nach Unsterblichkeit ist trotz aller Satire nicht totzukriegen. 120, 200 oder etwas mehr Jahre sollten in naher Zukunft schon drinliegen, denn ohne Jenseits schrumpft die Zeit. Dem Wohlstand entspringt der Anspruch auf eine maximale, konsumfreudige Lebensspanne. Es sind nicht nur Kryokonservisten und Transhumanisten, die unser Verfalldatum überwinden wollen. Alle Lebenswissenschaften folgen ihren Sirenenklängen, denn immer schon lechzte die Öffentlichkeit nach neuen Verheissungen; je vollmundiger, desto besser. Goethes Hausarzt Christoph Wilhelm Hufeland erfand die Mikrobiotik, das erste Grundlagenwerk der AntiAgeing-Medizin. Und was macht Faust im ersten Teil? Er trinkt aus dem Hexenkessel, und «fühlt mit innigem Ergetzen, wie sich Kupido regt und hin und wider springt». Für die forschende Männlichkeit ist nichts schlimmer als ein lendenlahmes Vegetieren. Die Geburtsstunden der Endokrinologie bringen subkutane Injektionen wässriger Extrakte von Meerschweinchenhoden, die Bakteriologie setzt auf Joghurt, Serge Voronoff wird in den 1920ern zum Medienstar mit der Transplantation von Schimpansenhoden an Menschen. Die Vasoligatur des Wiener Physiologen und Pioniers der Hormonforschung Eugen Steinach verjüngte eine internationale Klientel. Doch der Schweizer Arzt Paul Niehans schlug sie alle, indem er Prominenten wie Papst Pius XII., Pablo Picasso, Hemingway und Adenauer Zellen von Schafsfeten in den Gesässmuskel spritzte. Danach wurden lange Jahre Östrogene zum Jungbrunnen der Weiblichkeit. 2012 erhielten Gurdon und Yamanaka den Medizin-Nobelpreis für ihre Forschung mit Stammzellen. Yamanaka stellte als Erster aus Mäusehaut pluripotente Zellen her. Eine Verjüngung, die von der Presse enthusiastisch als «Backrezept für Unsterblichkeit» gefeiert wurde. Im Augenblick richten es Fitness und Nanotechnologie. Doch unbestreitbar rückt mit jedem Forschungsergebnis das Ziel der Lebensverlängerung einen kleinen Schritt näher.

Zweifel und Hoffnungen gehen Hand in Hand. Im ältesten überlieferten Epos scheitert der Held Gilgamesch auf der Suche nach Unsterblichkeit. Einmal überwältigt ihn der Schlaf, dann frisst ihm eine Schlange die Wunderpflanze. Dennoch, was wäre, wenn es doch einmal gelänge? Im Märchen «Der Gevatter Tod» versucht der Arzt den Tod zu überlisten, was er mit seinem eigenen Leben bezahlt, und in der oft erzählten Sage vom «Schmied von Jüteborg» kann der Tod nicht mehr von einem Apfelbaum herabsteigen, «so dass auf Erden niemand mehr starb und darüber viel Unheil entstand». Ein Thema, das auch der Nobelpreisträger José Saramago in seiner Geschichte «Eine Zeit ohne Tod» variiert, worin Altersheime und Spitäler zu Stätten des Schreckens werden. Mythen und Geschichtenerzähler sind sich meistens einig: Das ewige Leben ist ein Fluch. Paradebeispiel ist die Erzählung vom «ewigen Juden», die seit dem 17. Jahrhundert Dokumente und Dichtungen bis in die Gegenwart inspiriert. Ahasver muss wandern bis zum Jüngsten Tag. Sein Ende liegt hinter aller Zeit. Ein überlastetes Gedächtnis und die Trauer um Verstorbene sind noch die geringsten seiner Leiden. Wer die Grenzen des Lebens verwischt, ruft die Untoten auf den Plan. Sie sind noch im angehenden 18. Jahrhundert Gegenstand theologischer Disputationen und ärztlicher Untersuchungen. Den «Fliegenden Holländer» begleitet ein Heer von Zombies und Vampiren. Bis zu ihrer Erlösung treiben sie ihr Unwesen auf unsere Kosten, es sei denn, sie bevölkern Pubertätsromane und die Filmateliers von Hollywood. Die Alchemisten haben vergeblich das lebensverlängernde fünfte Element, die Quintessenz, gesucht. Dafür entdeckten sie den hochprozentigen Alkohol, in dem sie das Lebenswasser, aqua vitae, zu erkennen glaubten. Auch der «Stein der Weisen» blieb ihnen verborgen, dafür haben sie, nebst ihren Destillierkolben, Porzellan und Schnaps hinterlassen. Damit sollten wir uns begnügen, bevor uns «Der Fluch der Karibik» in tiefseefischige Wiedergänger verwandelt. 